\title{
OUTCOMES OF DISCRIMINATION VIOLATION ON WOMEN'S LIFE
}

\author{
Summer Sultana ${ }^{*}$ \\ Rakhshanda Bano ${ }^{* *}$
}

\begin{abstract}
It is said that the major significant role is played by women in the development of society. However they suffer from numerous problems in our society. To solve these problems, there is no systematic strategy, by which the woman's problems can be solved. Some acts of violence against women or laws have been passed but unfortunately are not emphasized on implementing these rules while numerous welfare organizations are playing an important role in our society but despite this, the act of violence is increasing day by day because of which deterioration is created in society. Violence in any type causes serious and negative input on women's lives. Women's life does not only socially disturb and dissatisfy but also mental stress become a cause of various mental illnesses. Furthermore many women are facing persecution in a society. They tolerate worse circumstances due to future of their offspring as they are economically dependent on husband, therefore, they have to compromise their difficulties and troubles. Many women isolate the conjugal life due to violence by the husband or by the in-laws. Even then, these women are the victims of violence but they tolerate different complications and troubles in social life and they also bear the financial problems. Children are equally disturbed and in order to bring a change in their life mother has to financially struggle for the progeny. A mother must also be educated in these circumstances, as things can get worse if she's not educated and the result is that she is dependent on others.
\end{abstract}

Keywords: Harassment, intimidation, distress, female, socio-economic, poverty, sexual-violation, mental-brutality

\section{Introduction}

The violation against women is a serious issue. It is not only limited in specific region but it exists in the whole world in a huge form and in any kind of persecution. This issue has been described by the several authors. Numerous reports have been presented about the cruel behavior with women from around the world. Everyone can easily know the situation related to this problem. Which society is very different to other society but even then same crimes are committed related to the discrimination against female population. Government needs to give attention to this issue. The atrocities against women make them vulnerable for not only physical but mental illness.

\footnotetext{
* Summer Sultana, Ph.D. Associate Professor, Department of Political Science, University of Karachi

** Rakhshanda Bano, Ph.D. Student, Department of Political Science, University of Karachi
} 
The objective of this study is to describe the consequences of violation against women and aware the people from bad impacts of any type of violation. Women related crimes are increased day by day. According to the report of UN Secretary-General, "Violence against women takes many different forms, manifested in a continuum of multiple, interrelated and sometimes recurring forms. It can include physical, sexual and psychological/ emotional violence and economic abuse and exploitation, experienced in a range of settings, from private to public, and in today's globalized world, transcending national boundaries."

Violation exists in huge forms in the world like that where the persecution are not found in any form related to women. Some countries have failed to abolish the savagery against females while some other countries are engaged in reducing violation.

Violation against women issue is a human rights matter. It is a not limited to Pakistan but it is a worldwide issue. Many laws are made for reducing violation against women on governmental level and on international level but there are no emphasize on implementation of laws in society and according to the law does not give punishment to the culprit.

The incidents of violation against women like burning of girls and brides by the in-laws and husband, acid throwing and rape incidents are shown on media every day but violation against women issues are not solved by the government therefore the incidents of violation are not reduced. Women are being mistreated and this is based on several reasons. Women easily become target of persecution. Women are becoming victims of violation not only on the domestic level but they have to face different types of violence at workplace as well some of these are; coercion, harassment and insulting behavior. Women are adversely affected from these types of violation.

According to the World Health organization's population based studies report that between $12 \%$ and $25 \%$ of women have experienced attempted or completed forced sex by an intimate partner or ex-partner at some time in their lives." 2

The gender discrimination or gender inequality is main cause of persecution in the society against females and due to this they face horrendous consequences in their lives. The objective of this research is to investigate the outcomes of any type of injustice behavior against female gender. Some cruel attitude is based on domestic level between wife and husband, while others face brutality at workplaces during jobs and numerous bear to social violation. Whether any type of assertiveness it become a cause of obstacle of the society and distorts the personality of a person psychologically and put the impacts on the physical health.

The number of reported cases of erotic cruelty is very dangerous that are contain on intimacy, sex trade by force, to coerce for delivery of child, desire for illicit sexual relation, unusual sexual practices that may be hurtful for the life of women, illegal erotic

${ }^{1}$ PPDVP Kiribati Final Report 2006 and Kiribati Family Health and Support Study Initial Finding Reports, p. 27, Available on http://countryoffice.unfpa.org/pacific/drive/KiribatiFamilyHealthandSafetyStudy.pdf ${ }^{2}$ Ibid, p. 28 
relationship with other female, affront on the basis of sex, disgrace, obscene films are shown forcibly. "Abnormal sexual behavior that can have detrimental effects on women",3

Victim bear disturbances, not only physically but also psychologically and suffer from discomfort and anxiety. The responsibility of the state's government is to take positive steps to prevent such incidents but the attention is not given seriously by the government towards the issues of female related persecution.

According to the concept of Liz Kelly "the common character underlying the many different forms of violence [as being] the abuse, intimidation, coercion, intrusion, threat and force men use to control women."

\section{Research Questions}

The research questions about the maltreatment with women are as follows:

- How to control the female related crimes which are increasing very fast?

- How awareness can be ensured to people related to these matters about female which is caused by the deterioration of the society?

\section{Literature Review}

In many societies, women are preferred over men from distant past. Females were not given rights related to the any property. Oppression against women is considered societal and lawful by the men. All the rituals and traditions of Subcontinent had very deep influence on Muslims Indo-Pak. The practices of these customs slowly became strong. Consequently their rights were trampled. Thus the concept of servitude related to women assimilated into society. From the period of forefather they are acting upon customary practices inequality. The several elements are also found in society which becomes a cause of inferiority of women in numerous countries. "The authority of a man over her allows him to use violence that was considered a legal rights and social acceptance. ${ }^{5}$

There are two aspects of violation causing mental and physical harm. This word is usually used for the man persecution against female. The word violence is not limited to the persecution but it has huge meanings and forms, the domestic abuses, intimate partner violence, harassment in workplace, rape and all kinds of rape (gang rape, marital rape etc) cruel behavior by in-laws, mental torture, sexual intimidation, sexual

\footnotetext{
${ }^{3}$ Hasrat M.H, Pfefferle Alexandera (June 2002) Violence Against Women In Afghanistan, (Biannual Report) Kabul: Afghanistan Independent Human Rights Commission, p.5, Available on www.aihrc.org.af/media/files/VAW_Final\%20Draft-2012.pdf

${ }^{4}$ Coy Maddy (2016) Prostitution, Harm and Gender Inequality: Theory, Research and Policy, (New York: Routledge), p.36

${ }^{5}$ Pakeeza, Dr. Shahzadi (6th Vol 2015) Domestic Violence Laws And Practice In Pakistan, (Rawalpindi: Transactions on Education and Sciences), p.1, Available on vfast.org/index.php/VTESS/article/download/205/296
} 
humiliation, burning attack, child sex underage girls marriages and other form come into the context in the violence. Some cases are reported and some cases have to be unreported. The information of many violation cases has not been existed in official records.

All types of violence does not only destroy the personality but also damages the psychology of women. Victims have to tolerate different types of troubles after the incidents of violation. The rape, beating by the husband, pushing pulling hair, torture on the different parts of body and burning by the in-laws are the major examples of social violation. The psychological violation is consisted on taunting; criticize on personality, blaming, angry without any reason, or mistake.

The post traumatic disorders are created in victims. After the attack of rape, victim feels the pain in different parts of body, all the scenes are flashback, fear, suicidal tendencies are increased, external injuries in various parts of body and victim also wounds internally during sexual attack and pregnancy may be more possible in victim. If violation to women is occurred during pregnancy it may cause poor health of mother. During the birth of child, deficiency of blood and loss of weight of the child are also a major risk, for the mother and child both are the causes of violation. Burning attack whether fire or acid throwing, the victim is badly affected by this attack. Sometimes the patient is totally burn by acid throwing due to acid assault. The psychological problems are created from mental torture. The victim is not able to work at all as the victim experiences headaches, tension, pain, disturbance of sleep, stomach complain, and the victim feels tired from the mental torture.

Elizabeth expresses her feelings about cruel behavior: "This does not mean that all women occupy the same position in relation to safety and violence. Many other features of their lives... will mean that their circumstances differ. Somehow, through as all women reach adulthood, they share a common awareness of their particular vulnerability. Learning the strategies for survival is a continuous lesson about what it means to be female."

On the contrary she says:

For men, there are no tips about personal safety in crime prevention handbooks. It is assumed that men either know about avoiding dimly-lit alley ways and bus stops, or that they are able to protect themselves. While we may assume men already know how to protect themselves, they don't seem to be very successful: men's recorded levels of victimization are much higher than women's. ${ }^{7}$

The sexual violence is a common form of discrimination behavior against women. The proportion of these type of cases is increasing day by day not only in Pakistan but also in the whole world. Rape, prostitution, gang rape and marital rape are the most common forms. Pakistan's government is not taking serious measures in order to control the crime rates. They need to take positive action against unlawful behavior.

${ }^{6}$ Ibid, Greenan Lily, p. 24

${ }^{7}$ Ibid, p. 24 
The effects appear any violence against women on the basis of gender difference whether any ethnicity, color and cast. The women are mostly vulnerable to persecution by men. There are many causes that lead to the increase in violence like impoverishment or financial hardship etc. According to the investigation, large number of women are the victim of abusive behavior and they face such hardships repeatedly. They endure for any type of violence. "Women are mostly at risk from men they know."

\section{Discussion}

\section{Sexual Intimidation}

Most of the females are victim of harassment and they face the mental illness and have to bear distressing situation. According to a research the emotional feelings are found in ninety six present prey of sexual intimidation. Many people retain their activities in difficult time at workplace and do not leave their professional responsibilities due to financial problem so most of the people end up tolerating the somatic discomfort. Thomas argued that "Sexual harassment is simply not something that employers can wholly prevent without taking extraordinary measures constant video and audio surveillance, for example that would revolutionize the workplace in a manner incompatible with a free society."

Financially also have adverse effects on victims. It is not only literacy point of view but also progress and development is also affected on it. The re-employment in the harsh conditions on the work place or then transfer to another place away from the family is not possible therefore most of the women are not able to continue their professional activities on this basis. Due to this they have to bear the financial difficulties or joblessness. Its impacts on the workplace become obstruct in their work performance. According to the law of court, "An employer could sexually harass a female employee with impunity by carefully stopping short of firing the employee or taking other tangible actions against her in response to her resistance." 10

Due to harassment the effected women have to bear the difficulties related to work place. They also face somatic and psychological anguish along with financial disadvantages. The NIOSH institution described the report that the female who connected to any profession they are more vulnerable as compared to male. They have to tolerate the strain and tension related to it. The MacKinnon says that about sexual harassment "Legally women are not arguably entitled, for example, free of rape, nor are women legally guaranteed the freedom to walk down the street or into a court of law without sexual innuendo."11

Jewkes, Sen \& Garcia-Moreno describes the commits in these words in 2002 "Any Sexual act, attempt to obtain a sexual act, unwanted sexual comments or advances, or acts to traffic, or otherwise directed, against a person's sexuality using coercion, by any

\footnotetext{
${ }^{8}$ Ibid, p. 23

${ }^{9}$ Saguy Abigail C (2003) What is the sexual harassment?, (California: University of California Press), p. 35

${ }^{10}$ Ibid. p. 32

${ }^{11}$ Ibid. p.30
} 
person regardless of their relationship to the victim, in any setting, including but not limited to home and work." 12

Several advancements are not unknown to works and it not only affects mentally but physically as well. It has adverse effects on any work place, providing knowledge regarding taking measures in order to prevent these sexual harassing actions are really important but it is yet not sufficient. "It can have devastating efforts on women's health and well-being, as well as serious negative outcomes for organizations and institutions where women work and attend school." ${ }^{13}$

The mental strain complaints are found in women effected by the sexual harassment which is the result of distressing. According to a research, the sentimental disquietude exist in ninety six percent of the professional work of victims is affected in half percent survivors. Some of them are victimized to body stress. Not only somatically but also the aspect of mentally the bad outcomes of it on women victim. "About half suffered work performance stress, and over a third had physical stress problems." 14

\section{Common Physical and Emotional Reactions}

- Poor concentration at work

- Stress on personal relationships

- Fear/Anxiety/worry

- Debilitating depression

- Sleep/weight problems

- Alcohol or drug use or smoking

- Staff turnover

- Increased absenteeism

- Tarnished department/company reputation

- Increased payouts for sick leave and medical benefits

- Vulnerability to hostile confrontations

- Legal and consultant costs

- Lower staff productivity

- Poor staff morale

- Less teamwork

Source: Saima Manzoor Arain, Women Police Un furled in Pakistan: Perspective, Status and Prospective, 2014, pp. 134-135

The sexual intimidation relies on strength. Women are destroyed somatically and psychologically from harass. Fright, stress, uneasiness, irascibility and the feeling of loneliness are found in these victims and create feelings of estrangement and this

\footnotetext{
${ }^{12}$ Renzetti Claire M, Edleson Jeffrey L et al (2nd Ed 2011) Sourcebook on Violence Against Women, (London: SAGE Publication), p. 98

${ }^{13}$ Gullotta Thomas P, Bloom Martin (2nd ed 2003) Encyclopedia of Primary Prevention and Health Promotion, New York: Kluwer Academic/Plenum publishers, p. 975

${ }^{14}$ Boland Mary L (1st Ed 2002) Sexual Harassment: Your Guide to Legal Action, Naperville: Sphinx

Publishing, p.32
} 
reduces the confidence. Physically its immediate outcomes appear vomiting, stomach related problems, insomnia, weight reduction, whining, teeth clenching and fatigue. "Among the emotional reactions reported by the women were fear, depression, anxiety, irritable, irritable, feelings of low self-esteem."15

Woolf scholar Suzette Henke has said that about the harassment: "Much of the impetus women's life-writing in this century has been connected by emotional webs and filaments to a wide range of traumatic episodes many of these experiences have had a profound impact on the construction of female subjectivity; and a number of women authors have instinctively turned to modes of autobiographical expression to implement the kind of healing made possible through the public inscription of personal testimony." 16

Desperation is created as adverse effects, the life has adopted a new turn and the other problems are gotten increased, for example job loss from which the earning is closed and the performance is also interrupted at workplace. Many cases of violation against women are such that are un-solved and have to tolerate the difficulties for legal procedures and legally they do not get justice in the courts cheaper and soon.

The effects of harassment are consisted on physical and psychological results in which the health issue is contained regarding mental and body condition and changes in the quality of work and impacts on future and career. "The aftereffects are influenced by disappointment in the way others reacts."17

It is commonly believed that women who are victim of sexual harassment, the mental strain is found too much in them while in comparison with men. Similar symptoms are identified in those men and women after the attack of sexual intimidation. The shocking situation comes as a result of it which has been defined in the Manual of American Psychiatric association. "Many writers have speculated that gender-based abuse is related to the high rates of depression among women compared to men."18

In some studies on the impacts of sexual threatening the adverse effects on women is considered center of attention but the adverse impacts on the organization is rarely described. The less content is existed in written form on the basis of events. Under the kind logical thought the organization is not damaged from the harassment. In general, the scant literature available is highly speculative and anecdotal." 19

\footnotetext{
${ }^{15}$ Paludi Maichele Antoinette (1987) Ivory Power: Sexual Harassment on Camus, (New York: State University of New York), p. 69

${ }^{16}$ Caronia Nancy GiuntaEdvige (2015) Personal Effects: Essays on Memoir, Teaching and Culture in the Work of Louise DeSalvo, (New York: Fordham University Press), p. 163

${ }^{17} \mathrm{O}$ ’Toole Laura L, Schiffman Jessica R et al (2nd Ed 2007) Gender Violence: Interdisciplinary Perspectives, (New York: New York University Press), p. 144

${ }^{18}$ Ibid. p. 146

${ }^{19}$ Ibid. p. 148
} 


\section{Adverse Effects on Children}

Children become victim of mental anguish and adopt the negative attitude. Sometimes it is based on long duration and ever short term. Such issues become a cause of psychological illness like mental strain, uneasiness, self-reproach, scare, sexually unable and abolition etc. It base on the nature of the abuse. The afraid and disquietude are created from the anti-gender existence in the survivor of these violation. It shows the contraband sexual deeds. "From mild to severe, in both the short and long-term."20

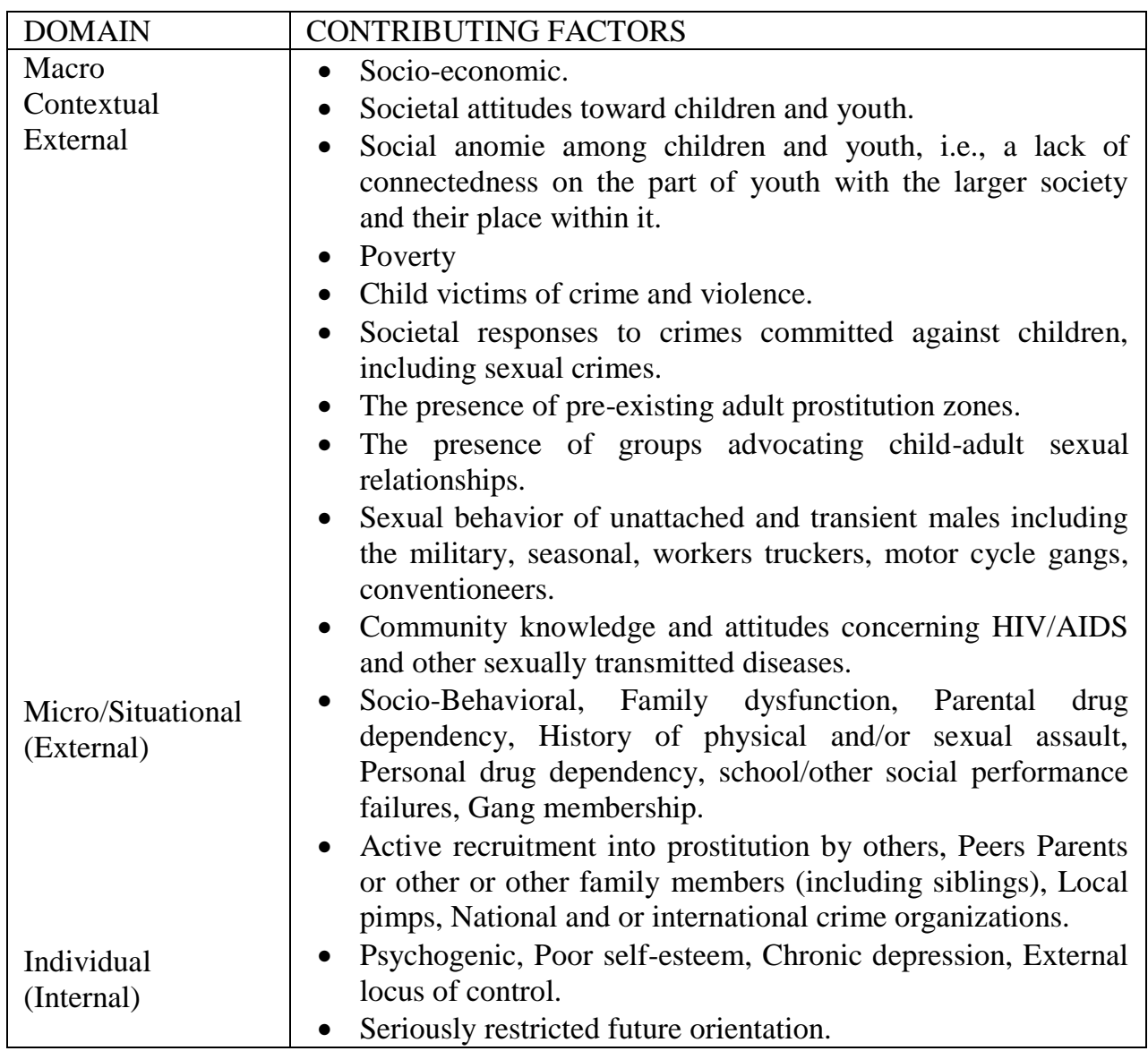

Long-term effects of sex-related violation adversely affects the mental health of children. Children who are the victims of sexual assault in childhood, the mental illness is usually found in them. They become victims of very high nervousness as a response they can do such attitude themselves and they can become a cause of devastation

\footnotetext{
${ }^{20}$ Deb Sibnath, Mukherjee Aparna (2009) Impact of Sexual Abuse on Mental Health of Children, (Calcutta: Concept Publishing Company), pp. 34-35
} 
attitude for example drug and alcohol addicts, "Adults who were sexually abused as children commonly experience depression." ${ }^{21}$

\begin{tabular}{|c|}
\hline SHORT TERM EFFECTS \\
\hline $\begin{array}{l}\text { - Preoccupation with sexual matters } \\
\text { - Premature development of adolescent interests } \\
\text { - Promiscuity } \\
\text { - Despair } \\
\text { - Molestation of younger children } \\
\text { - Venereal disease Increased or public masturbation } \\
\text { - Prostitution } \\
\text { - Pregnancy }\end{array}$ \\
\hline LONG TERM EFFECTS \\
\hline $\begin{array}{l}\text { Problems in Sexual Adjustment } \\
\text { - Promiscuity } \\
\text { - Avoidance of sexual activity } \\
\text { - Incestuous relationships } \\
\text { - Many unwanted pregnancies } \\
\text { - Sexual molestation of children } \\
\text { - Unsatisfactory sexual relationships } \\
\text { - Homosexuality }\end{array}$ \\
\hline EDUCATIONAL PROBLEMS \\
\hline $\begin{array}{ll}\text { - } & \text { Truancy } \\
\text { - } & \text { Sudden disruptive behavior } \\
\text { - } & \text { Depression withdrawal from usual activities } \\
\text { - } & \text { Collapse of self-esteem } \\
\text { - } & \text { Learning difficulties }\end{array}$ \\
\hline Psychological Symptoms \\
\hline $\begin{array}{l}\text { - } \text { Low self-esteem and long-lasting sense of helplessness } \\
\text { - } \text { Behavior which causes injury to herself } \\
\text { - } \text { Obesity } \\
\text { - } \quad \text { Chronic depression } \\
\text { - } \quad \text { Schizophrenia } \\
\text { - } \quad \text { Murder or interpersonal violence } \\
\text { Eating and body image disorders }\end{array}$ \\
\hline
\end{tabular}

Deb Sibnath, Mukherjee Aparna (2009) Impact of Sexual Abuse on Mental Health of Children, (Calcutta: Concept Publishing Company), pp. 36-37-38

\footnotetext{
${ }^{21}$ Ibid. p. 35
} 


\section{Underage Girls Marriages}

The adverse effects of early marriages on children and the different types of complications are created. Underage girls cannot understand the house-hold matters after marriage because of immature age and they cannot continue their education and thus their education is interrupted, children have to toil and labor in early age in the household of their husband and moreover the education has to leave. The mental, somatic and emotive impacts come out as a result. Decreases their progress and getting education also causes of disruption. "Early marriage has deep physical, intellectual, psychological and emotional consequences." ${ }^{, 2}$

After early marriage the girls have to bear the burden of many descendent due to the sexual practice repeatedly and as a result they become a victim of fertility. The birth control pill is given by mutual consent of husband and wife. The distinction is found between the development and industrial countries related to the traditions of wedding. Such practices are for multiple births where the birth rate is too low. In such a situation both mother and baby's lives may be in danger due to being underage. Many problems are created are due to early maternity. "One important difference between marriage customs in many developing world societies and those in the industrialize world today." 23

\section{Sexual Humiliation}

According to the investigation of police related to rape "Depending on the passivity and fear of the victim, it is very possible that the offender's mere presence would be enough to control the victim. This is very difficult for a person who is removed from the actual situation and/or having a personality different from the victim's to accept. Quite often the investigator judges a victim's reaction on the basis of what he/she would do (or believes he/she would do), rather than taking into account the victim's personality, and the fear factor involve." 24

According to the survivor of fornication when the attack on her, the victim feels fear "I know the fear I went through and the fear of thinking that you are going to die. You can't describe it. It goes through your mind that you are not going to see your family again." 25

The fornication is connected to body attack. This crime enhances the traumatic disorder in effected women than other traumatic conditions. It is contained in other big issues due to presence in the large scale therefore post traumatic syndrome disorder patient is attached with fornication. According to the research of adultery sufferer, the diagnostic

\footnotetext{
${ }^{22}$ Okonofua Friday (16 Vol 2012) African Journal of Reproductive Health, (Nigeria: Women's Health and Action Research Centre), p. 96

${ }^{23}$ Ibid.

${ }^{24}$ Jordan Jan (2008) Serial Survivors: Women's Narratives of Surviving Rape, (Sydney: The Federation Press), p. 6

${ }_{25}^{\text {p. }} 6$ Ibid. p. 10
} 
standard is determined later of physical attack. "Because of its high prevalence compared with other extreme events."26

Not only bodily but also mentally impact appears in victim for short and long time. Soon After the physical assaults the sufferer feels badly afraid and set back. Due to these types of act of violence sexual organs are adversely damaged and are also wounded. Similarly they are also at risk of the break of other organ. The diseases are transferred through the body part and consequently the birth of child is more likely in female. "Women who are raped are also at risk of contracting sexually transmitted infections or becoming pregnant.", 27

The psychological impacts are also possible in female victim, uneasiness, mental stress, internal system become also a cause of breakdown; complain of other issues related to it, traumatic condition after raped and is also indicates the post traumatic syndrome disorder in the sufferer of fornication. Approximately (94\%) ninety four percent affected female victim of rape determines the post traumatic syndrome disorder after the short time of fornication. "Many of the experienced of rape survivors fall under the diagnosis of PTSD." 28

The survivor of adultery shares the effects of rape physically: "I guess that the pain is just too much to bear. I was violated and humiliated. They stole my virginity, which I valued very much. Even worse, I lived in a small town and the entire school found out about it. Rumors and various versions of the story were rampant, and in most of them I was portrayed as a slut and a whore who asked for it." 29

It has bad effects on whole life on the victim. She did not describe the adverse experience before it. That time she was feeling very uneasy and nervousness and is changed the temperament. Drowsiness is dominated but she considers herself to be responsible for adultery. She was very regretful for the wrong decision and for the protection due to not do something against rapist. She had to face the hassle, nervousness and tenseness. Moreover lack of slumber, a sense of loneliness, to be afraid of male and to recall the event in the mind repeatedly. "She blamed herself for using poor judgement and for not fighting back." 30

Appears the clear signs of rape psychologically like upset, dread, the fear is found for their protection and again and again startle, lost the trust, to face uncertainty and repeatedly crying after the physical assault, mental strain is enhanced too much, most of them are killed themselves to get the redemption of this trouble. The traumatic condition

\footnotetext{
${ }^{26}$ Gerrity Ellen, Keane Terence M et al (2001) The Mental Health Consequences of Torture, (New York: Kluwer Academic/Plenum Publishers), p. 180

${ }^{27}$ Weiner Irving B, Craighead W. Edward (4th Ed 2010) The Corsini Encyclopedia of Psychology, (New Jersey: John Wiley \& Sons, Inc), p. 1420

${ }^{28}$ Ibid.

${ }^{29}$ Marmion Shelly L (2006) "Intimate" Violence Against Women: When Spouses, Partners, Or Lovers Attack, (USA: Praeger Publishers), p. 64

${ }^{30}$ Ibid.
} 
after rape is found in them. "Acute stress responses such as shock, disbelief, confusion and crying often occur immediately after the incident.",31

According to Woolf scholar "The public and the private worlds are inseparably connected; and the tyrannies and servilities of the one are the tyrannies and servilities of the other" But Herman gives the comments oppose to the Woolf "It is now apparent also that the traumas of one are the traumas of the other." 32

\section{Burning Attack}

The victim has to face the catastrophic impacts of acid attack and whole life they bear the trouble and is gotten distortion. Deprivation of eyes, injury are tolerated every next day. Sometimes the victim loses her life by the acid attack. They are shocked badly physically and mentally. Mostly the survivors are not taken the legal help. The physical and mental resources are their out of reach. They do not get the support by any means. They have to go through the psychological condition like stress, lack of sleep, the fright to in front the outside people, mental illness, to kill themselves, the fear of disgrace in the society they have to face many problems related to it including degradation and bias. They compel to live somewhere else. "The trauma of an attack often results in depression, insomnia; fear of facing the outside world, and, in some cases, psychosis and suicides." 33

The violent behavior is adopted with several females. Their physical condition is worse. Lack of confidence and do not able to do work. The victims of acid throwing are more afraid every time. Potential power becomes dupe to the violence. The negative influences affect have on close relation. Such concept should exchange the concept of which women have right. "As a result, they may develop poor interpersonal relationships." 34

The several form of contravention against women impact on victim on body differently. Wife has to tolerate the misbehavior by the husband for that reason she has to face to due physical problems like sleeplessness, stomach problems, menstrual problem, lack of appetite, head ache and muscular pain. Such females who has small foots they face to trouble for walking. "Women who suffer from intimate partner violence often suffer from chronic headaches." $" 35$

AIDS is very high risk in them. Inside body damages is possible in the case of fornication and genocide. They have to face more pain due to breakdown of the sex

\footnotetext{
${ }^{31}$ Ibid. p. 65

${ }^{32}$ Ibid, Personal Effects, p. 164

${ }^{33}$ Solotaroff Jennifer L, Pande Rohini Prabha (2014) Violence Against Women and Girls: Lessons From South Asia, Washington DC: International Bank for Reconstruction and Development, p. 56

${ }^{34}$ Parrot Andrea, Cummings Nina (2006) Forsaken Females: The global Brutalization Of Women, United States of America: Roman \& Littlefield Publishers Inc, pp. 191-192

${ }^{35}$ Ibid. p. 193
} 
organs for short time and sometimes they are died. Victimization is "an instrument of social control of women."36 (Khalid, 1997)

According to Mezey and Stanko in 1997 "Rape-associated fears such as fear of the dark, fear of of strange men, fear of the sexual act . . . fear of the consequences of rape, and . . . fear related to the woman's sense of her own vulnerability.",37

The financial situation is also a cause of abuses against women such as sex trade. Woman is also a victim of sexual atrocities due to financial difficulties. Judicial assist and expenditures of physical checkup is a reason of brutality behavior with female existence. "According to the World Bank, in established market economies, recent studies reveal that gender-based violence is a significant cause of death and illness in women, the result of beatings during pregnancy, marital rape, sexual abuse of girls, forced sterilization, abortions performed in unsanitary conditions, malnutrition, restricted access to health services, and a number of other abuses." 38

The cruel attitudes in different types become a part of life of female. Bad somatic changes are occurred which are clearly visible to everyone. The impact of any kind of violence whether physical, psychological or related to financial, it adversely effects on women. Not only physical but also psychological condition becomes poor from the brutal behavior. It is not given special priority. The shocking condition may be initially but later may be higher, their somatic conditions are worse. "Mental and emotional health are seriously jeopardized by violence but may be less noticeable."39

\section{Methodology}

Some part of this research is included on qualitative and the research method is consisted on the books. Some material of violation against with effects is taken from web articles. The tables have been defined about the effects discrimination of women. The facts and figures have been described in this study. Some books have been taken from the web site and other books are taken from library. This research is also depended on impact of violation against women.

\section{Conclusion}

Until and unless social norms improve and stereotypical ideas and concepts are eliminated from society, the violence against women cannot be saved. Its destructive impact on women's lives is destroyed. Not only female but also children's psychology is badly affected who are existed in such houses where women face several abuses. Whether domestic violence or the other types of abuses related to women makes disable to women. The ignorance must be eliminated for ending violence against women. Besides all the outdated practices which contribute to violence. It should be possible to ban these practices.

\footnotetext{
${ }^{36}$ Ibid. p. 192

${ }^{37}$ Ibid. p. 197

${ }^{38}$ Ibid.

${ }^{39}$ Ibid. p. 199
} 
One side in modern times, women experiencing worst torture and cruelty while the other side the females are working alongside of men but they are more progressing than males nevertheless they have to face many problems whether household or workplace related issues like sexual harassment etc. Gender-based differences encourage negative attitude against them and domination of men is a main cause of violation and it makes empower to men on women.

Physical violation or psychological both of them become a cause of illness. Sometimes the revenge against them becomes cause of violence. These women live their life unhappy as compared to other women. In the case of some violent incidents have to face many criticisms in the society and the blame is given by the society. Not only mentally but also bodily, the victims become ill. The emotional tendency is increased in these victims. The post traumatic disorder is found in these victims and the symptoms of (PTSD) become appear in victims.

Women play an important role in society. If one side man is responsible for the earning of money, or other side the woman is also responsible for the household related work, look after the house and nourish of offspring but nevertheless women easily become a victim of aggressive behavior of men. The short and long-term consequences come out related to violation against women. Short-term psychological and physical effects are removed with time but long-term effects are not removed easily and all type of violation increase the risk of poor health. Physical and sexual torture may be extremely serious. They live fearful life, the mental condition is not satisfied and these types of effects come in the generation. Tolerate the oppression, the feeling of deprivation of liberty and disturb the private and public life are the result of violation.

Government should make such laws which protect the effected women. The domestic violence laws must be enforced for the protection of women. Some laws have been made but these are not implemented in society by the government.

According to Islam man and woman are equal. There is no difference between them except some limitations. Islam gives the right to women than other religion but people do not follow the orders of Quran. 